\title{
MAXILLOFACIAL AND MANDIBULAR PHENOTYPES IN THE SKULLS OF RED SOKOTO AND SAHEL GOATS IN NIGERIA: THE ROLE OF DENTAL
} ABNORMALITIES

\author{
OLOPADE, J. O. ${ }^{*}$, SAMUEL, M. O${ }^{1}$, ANTIA, R.E ${ }^{2}$ and ONWUKA, S. K¹. \\ ${ }^{1}$ Department of Veterinary Anatomy, University of Ibadan, Nigeria \\ ${ }^{2}$ Department of Veterinary Pathology, University of Ibadan
}

*Correspondence: jo.olopade@ui.edu.ng : Tel +234(0)8023860829

\begin{abstract}
SUMMARY
This work examined phenotypic expressions in the anatomy of the mandible and maxillofacial region of the Red Sokoto and Sahel goats in Nigeria. The infraorbital foramen was placed above premolar two (PM2) in Red Sokoto but above premolar one (PM1) in Sahel. The Red Sokoto displayed interdigital septa (ruggae) which entered into mediolateral depressions of the opposing mandible but this was less prominent in the Sahel. Dental abnormalities were more pronounced in the Red Sokoto on the maxilla and mandibular rows. The facial and mandibular tuberosities were more prominent in the Red Sokoto goat and found to be more conspicuous in this breed with dental abnormalities. There was no significant difference between Calcium and Phosphorus in the craniofacial bones of goats with dental abnormalities compared to those without dental abnormalities in both breeds and in conclusion we thus suggest that the harsh environmental conditions of arid North West may be a greater predisposing factor for the negative dental profile of the Red Sokoto breed.
\end{abstract}

KEYWORDS: Maxillofacial, Mandibular, Phenotypes, Goats, Dental Abnormalities

\section{INTRODUCTION}

Regional anatomy is directly concerned with the form and relationship of all the organs present in particular parts or regions of the body and has immediate application to clinical works (Dyce et al., 2002). It's been reported that unique craniofacial aspects of the anatomy of any animal could serve as indices for the morphophysiological interpretation of the biokinetics and biomechanics of mastication (Terai et al., 1998, Olopade, 2006), and the evaluation of the effect of the interaction of the environment and the animal on the skull typology (Endo et al., 2002).
There are few reports on the dental profile of ruminants in Nigeria. Kene and Agbo (1998) and Kene and Uwagie-Ero, (2001) reported that dental caries, teeth fracture, impacted molars, oligodontia and supernumerary teeth amongst others were seen either in cattle or goats in Nigeria.

In continuation of our work on the craniomorphometry of small ruminant breeds in Nigeria (Olopade and Onwuka, 2005a; 2007; 2008; Shawulu et al., 2008) we report on phenotypic expressions in the maxillofacial and mandibular regions of the Red Sokoto and Sahel breeds of goat, the implications of dental abnormalities and the possible role of Calcium/Phosphorus profile of the craniofacial bones. 


\section{MATERIALS AND METHODS}

A total of 54 goats were used for this study comprising of 30 (21 males, 9 females) Red Sokoto, and 24 (15 males, 9 females) Sahel goats. The animals were obtained from their local habitations in the north western and north eastern parts of Nigeria respectively. All animals were aged by dental eruptions, restrained and slaughtered through quick decapitation and rapid bleeding thereafter the skulls were macerated following the techniques of Onar (1999), Olopade and Onwuka (2005b). Landmarks in the maxillofacial and mandibular regions including dental profiles were studied in each skull and recorded while photographs were taken using a Sony® digital camera.

Sample bones from adult Red Sokoto and Sahel goats were taken from parietal bones and mandibles, washed in deionised water and then dried before being digested in trioxontrate $\mathrm{V}$ acid $\left(\mathrm{HNO}_{3}\right)$; the elemental content of Calcium, Phosphorus were determined using the atomic absorptive spectrophotometer (AAS) while the Calcium/Phosphorus level was calculated.

Data was subjected to statistical analysis presented as Mean \pm SD and compared using the student ' $t$ " test of 5\% level of confidence.

\section{RESULT}

The infraorbital foramen was placed more above premolar two in the adult Red Sokoto but more towards premolar one in the Sahel goats. The foramen was in most cases a single foramen but in about $20 \%$ and $30 \%$ of Red Sokoto and Sahel goats respectively, a tiny bony perforations could be seen rostral to the double opening of the infraorbital foramen. Also in both breeds, the maxilla had a short communication dorsally into the nasal bone (Fig. 1).
A tiny foramen in both breeds were seen in many cases ventral to the root of the first premolar tooth and was also seen though less frequently in the inter alveoli space. A double opening of the mental foramen (close to each other) was seen in $15 \%$ of Red Sokoto and $30 \%$ of Sahel skulls. The mental foramina in the Red Sokoto were exceptionally large and in most cases elongated but were complete spheres in the Sahel. In both breeds, asymmetry in the morphology of the mental foramen was seen; for example, while it was double and closely knit on the left, it could be a large single foramen on the right and if double, could be far from each other on the interalveolar space.

The median surface of the mandibular symphysis displayed large interdigitating septa (ruggae) in the adult Red Sokoto (Fig. 2) that entered into large mediolateral depressions of the opposing mandible; these ruggae were less prominent in the Sahel. The facial tuberosities were more prominent in the Red Sokoto compared to the Sahel (those of the Red Sokoto were situated dorsal to the fourth or fifth cheek tooth, while that of Sahel was between the third and fourth cheek tooth); both facial and mandibular tuberosities were however more prominent in Sokoto goats with dental abnormalities (Fig 3 and 4) and are seen as a conspicuous facial tuberosities with the pointed extremity close to the root of the alveolus. Dental abnormalities were rarely seen in the Sahel skull but observed in the Red Sokoto breed. The pathologies observed included marked attrition of the occlusal surfaces, dental calculus, missing teeth, tooth fractures and sharp enamel points.

The level of Calcium and Phosphorus in the macerated skull of the Red Sokoto was higher than that found in the Sahel but the $\mathrm{Ca} / \mathrm{P}$ ratio though similar tended more to the ideal $2: 1$ in the Sahel. There was no significant difference between the $\mathrm{Ca}, \mathrm{P}$, and $\mathrm{Ca} / \mathrm{P}$ ratio of both breeds between 
animals with dental abnormalities and those without.

Table I: Mean values of Calcium, Phosphorus and $\mathrm{Ca} / \mathrm{P}$ ration in $\mathrm{RS}$ and Sahel goat skulls.

\begin{tabular}{llll}
\hline Breed & Ca\% & P\% & Ca/P \\
\hline Red Sokoto & $65.44 \pm 7.61^{*}$ & $32.77 \pm 6.40$ & $2.05 \pm 0.37 *$ \\
Sahel & $45.45 \pm 8.12$ & $22.82 \pm 4.47$ & $2.02 \pm 0.0$ \\
Red Sokoto DA & $67.08 \pm 6.50$ & $33.95 \pm 5.60$ & $2.02 \pm 0.40$ \\
Red Sokoto WDA & $63.02 \pm 8.80$ & $30.99 \pm 7.40$ & $2.10 \pm 0.42$ \\
Sahel DA & $47.19 \pm 2.00$ & $21.52 \pm 2.20$ & $2.15 \pm 1.0$ \\
Sahel WDA & $45.70 \pm 4.20$ & $23.90 \pm 2.10$ & $1.91 \pm 0.20$ \\
\hline
\end{tabular}

*Significantly higher than equivalent value in Sahel breed

DA: Animals with dental abnormalities

WDA: Animals without dental abnormalities

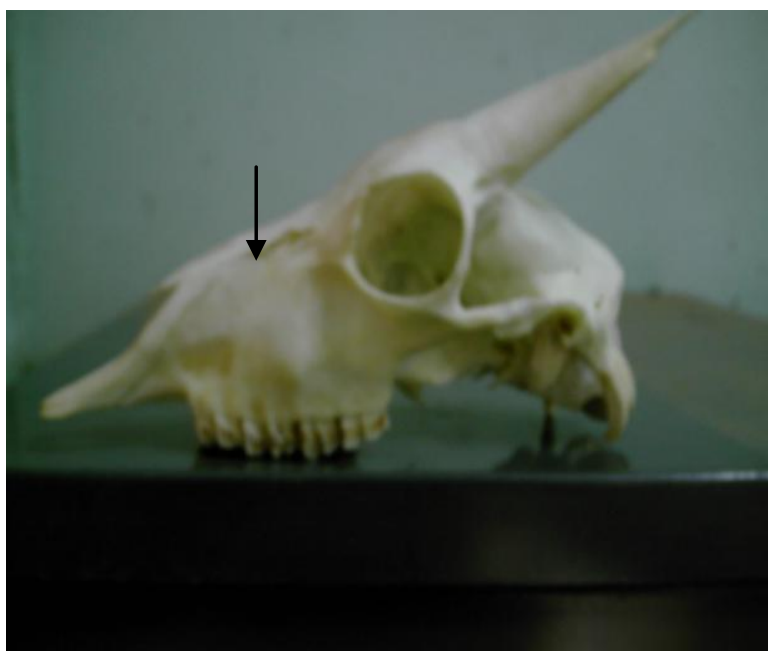

Fig. 1: Arrow showing interacting area between the nasal, incisive and maxilla bones

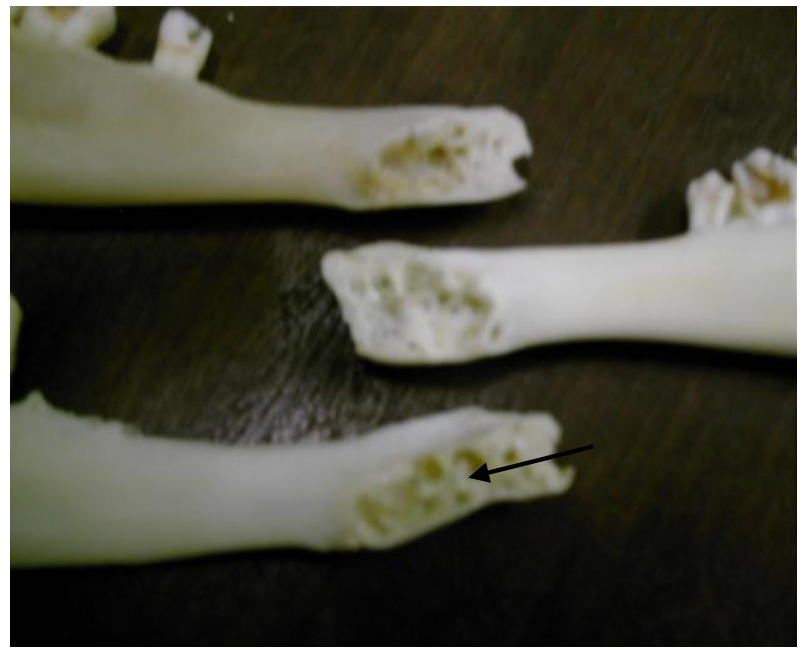

Fig.2: Arrow showing conspicuous interdigitating ruggae in the mandibular symphysis in the Red Sokoto Goat. From top down are the WAD, Sahel and Red Sokoto 

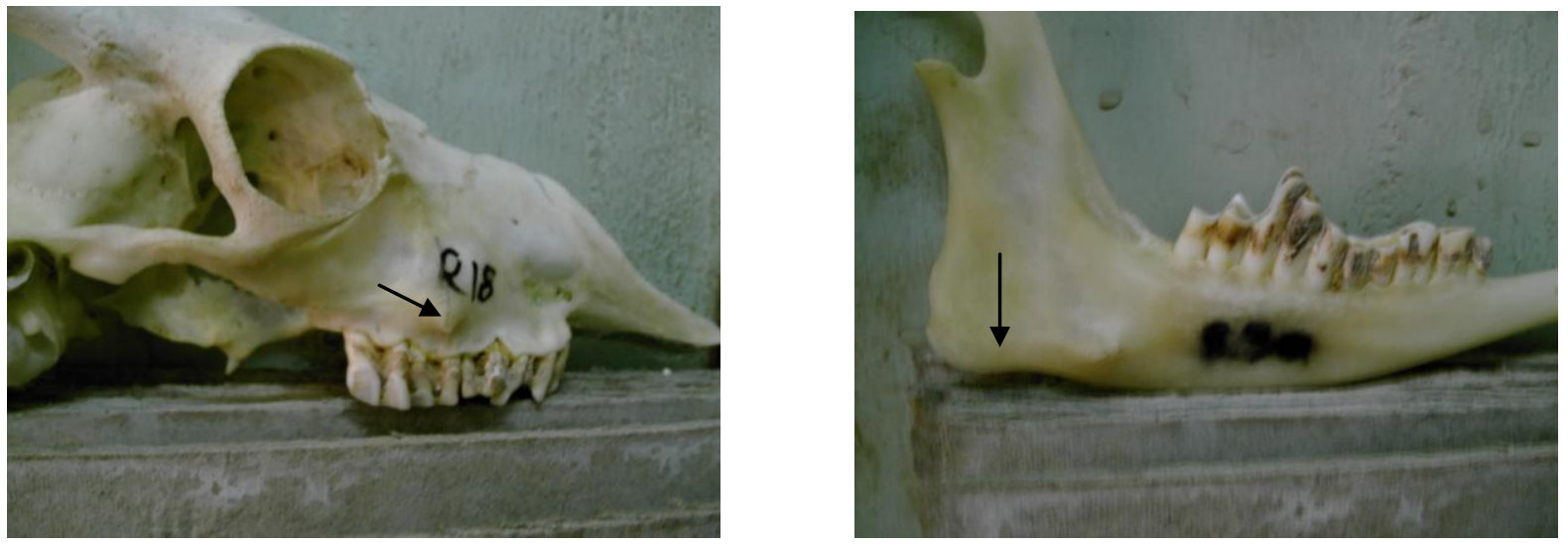

Figs. 3 and 4: Skulls of the Red Sokoto breed showing dental abnormalities in the maxilla and mandibular rows respectively. Arrows showing conspicuous maxilla and mandibular tuberosities. In Fig.3 (left), there is attrition of occlusal surface and deposition of calculi. Fig.4 (right) shows a disproportionate wearing and deposition of calculi

\section{DISCUSSION}

The infraorbital foramen was generally placed between premolars one and two, but like in the sheep (May, 1963), it was more of premolar two in adult Red Sokoto goats. The occurrence of accessory infraorbital foramen had been reported in man (Canan et al., 1991; Elias et al., 2004). The foramen in this study was in most cases simple and when it was double, it was just the presence of a tiny plate dividing the foramen opening into two as reported also in man (Elias et al., 2004). More work is needed to ascertain if this affects the morphology and functional anatomy of the infraorbital nerve in the goat. The position of the infraorbital foramen, relative to the premolar tooth is crucial to a successful regional anesthesia during dental extraction (Hall, 1971; Olopade and Onwuka, 2005a).

Dorsal to the opening of the infraorbital foramen in both breeds is the presence of tiny bony perforations which created a cribriform appearance similar to that reported in sheep (May, 1963). Dorsally, the maxillae have a short communications with the nasal bones, the incisive and lacrimal bones whereas in the sheep, the incisivo-naso-maxillary communition does not exist (Popesco, 1975).
The double openings seen in the alveolar space of some mandibles in both breeds suggest the occurrence of accessory mental nerve from the smaller foramen. The accessory mental foramen has been noticed in man (Toh et al., 1992; Hannihara and Ishide, 2001). This occurrence is clinically important because accessory foramen in the mandible have been known to transmit branches of nerves supplying the roots of the facial nerve and nerve block techniques by local anaesthetics might fail if any of these nerves or their branches pass through these accessory foramen escaping the nerve block. The presence of such foramina might also be an alternate route for tumor spread (Das and Suri, 2004).

According to Lieberman and Crompton (2000), animals that have unfused mandibles like the goat not only have a ratio of working to balancing side adductor muscle force of 1:1 but they also have their mandibles rotate independently during occlusion. Such independent rotatory movement is expected to be pronounced in the goat where the two halves of the mandible never fuse completely at the symphysis even in old animals (Olopade, 2006). The presence of an extremely rough symphyseal surface and marked reciprocal 
projections (ruggaes) and cavities in the Red Sokoto in comparison to the Sahel could be an adaptational feature to hold the symphyseal joint in the former which may not only be very loose but subject to more pronounced independent rotatory movements.

The dental abnormalities observed in this study were similar to those observed in goat and cattle in Nigeria (Kene and Agbo, 1998; Kene and Uwagie-Ero 2001). The relative lack of dental abnormalities in the Sahel (North East Nigeria) and predominance of the same in the Red Sokoto (North-West Nigeria) follow the same pattern seen in cattle breeds from both locations (Kene and Uwagie-Ero, 2001) where dental abnormalities were more in cattle from the north western region. This is most likely the result of browsing of tough dry matter due to scarcity of fresh vegetation which is most serious in the north western part of Nigeria (Kene and Uwagie-Ero, 2001). Individually, an analysis of the Calcium, Phosphorus and $\mathrm{Ca} / \mathrm{P}$ ratio did not reveal a reduced content of the minerals in the Red Sokoto breed indicating that the occurrence of dental abnormalities may not be primarily from reduced mineralisation of the craniofacial bones. However, the presence of prominent tuberosities in the maxillae and mandible, in Red Sokoto goats with dental abnormalities suggest a continuous and sustained mechanical strain of the skull due to increased activity of the masticatory muscles by the affected animals in an effort to ensure proper mastication despite the abnormalities; this may lead to a progressive worsening of the dental profile and ultimately affect the productivity of the animals through dysphagia. On the other hand, the prominence of the mandibular and maxillae tuberosities in the Red Sokoto breed compared to Sahel goats in the absence of dental abnormalities may be an adaptational response to physiologic masticatory strain on the skull and could be a prelude to dental abnormalities.

\section{ACKNOWLEDGEMENTS}

The authors are grateful to the technical staff and post-graduate students of the Department of Veterinary Anatomy, University of Ibadan, for technical assistance.

\section{REFERENCES}

CANAN, S., ASIM O.M., OKAN, B., OZEK, C and ALPER, M. (1991): Anatomic variations of the infraorbital foramen. Ann Plast Surg., 43: 613-617.

DAS, S and SURI, R.K. (2004): An anatomico-radiological study of an accessory mandibular foramen on the medial mandibular surface. Folia morphol (Warsz), 63: 511513

DYCE, K.M., SACK, W.O. and WENSING C.J.G. (2002): Textbook of Veterinary Anatomy $3^{\text {rd }}$ edition. W.B.Saunders Company Philadelphia. Pages 1-2

ELIAS, M.G., SILVA, R.B., PIMENTEL, M.L., CARDOSO, V.T.S., RIVELLO, $\mathrm{T}$ and BABINSKI, M.A (2004): Morphometric analysis of the infraorbital foramen and accessory foramina in Brazilian skulls. Int. J. Morphol., 22:213-218

ENDO, H., HAYASHI, Y., YAMAZAKI, K., MOTOKAWA, M., PEI, J., LIN, L., CHOU, C and OSHIDA, $T$ (2002): Geographical Variation of the mandible size and shape in the wild pig (Sus scrofa) from Taiwan and Japan. Zoological Studies, 41: 452-460.

HALL, L.W (1971): Wright's Veterinary Anaesthesia and Analgesia. $7^{\text {th }}$ 
edition. ELBS and Bailliere Tindall. London. Pages 53-66.

HANNIHARA, T and ISHIDA, H. (2001): Frequency variations of discrete cranial traits in major human populations. IV. Vessel and nerve related variations. J. Anat., 199: 273-284

KENE, R.O.C and AGBO, C.N. (1998): Dental abnormalities of three breeds of Nigerian goats. Trop. Vet 16: $15-23$.

KENE, R.O.C and UWAGIE- ERO, E.A. (2001): Dental Abnormalities of Nomadic Cattle of Nigeria. Tropical Trop. Vet., 19:191-199.

LIEBERMAN, D.E. and CROMPTON, A.W. (2000): Why fuse the mandibular symphysis? A comparative analysis. Am. J. Phys. Anthropol., 122: 517-540.

MAY, N.D.S. (1963): The Anatomy for the Sheep, 2nd edition. University of Queensland Press, Australia. Pages 267-281

OLOPADE, J.O. and ONWUKA, S.K. (2005a): Some aspects of the Clinical Anatomy of the Mandibular and Maxillofacial Regions of the West African Dwarf Goat in Nigeria. Int. J. Morphol., 23: 33-36.

OLOPADE, J.O. and ONWUKA, S.K. (2005b): Morphometric study of the skull of West African Dwarf Goat in South West Nigeria. Niger. Vet. J., 26:18-21

OLOPADE, J.O (2006). Comparative Morphometry of the Skull of three breeds of Goat in Nigeria. PhD thesis, Department of Veterinary
Anatomy, University of Ibadan. Ibadan, Nigeria.

OLOPADE, J.O. and ONWUKA, S.K. (2007): Osteometric Studies of the Skull of Red Sokoto (Maradi) Goats (Capra hircus): Implications for Regional Anaesthesia of the Head. Int. J. Morphol., 25: 407-410.

OLOPADE, J.O. and ONWUKA, S.K. (2008): A Craniofacial analysis of the skull of red sokoto (Maradi) goat (Capra hircus). Eur. J. Anat., 12: 57-62.

ONAR, V. (1999): A morphometric study of the skull of the German shepherd dog (Alsatian). Anat. Histol. Embryol., 28: 253-256.

POPESCO, P. (1975): Atlas of Topographical Anatomy of the Domestic Animals $2^{\text {nd }}$ edition vol. 1 W.B. Saunders Company. Philadelphia. Page 62

SHAWULU, J.C., KWARI, H.D., OLOPADE, J.O. and ONWUKA, S.K. (2008): Craniofacial studies of different ecotypes of the Sahel Goat. Trop. Vet., 26: 9-14.

TERAI, S., ENDO, H., RERKAMNUAYCHOKE, W., HONDO, E, AGUNGPRIYONO, S., KITAMURA, N., KUROHMADU, M., KIMURA, J., HAYASHI, Y., NISHIDA, T. AND YAMADA, J (1998).: An Osteometrical study of the cranium and mandible of the lesser mouse Deer (Chevrotain), Tragulus javanicus. J. Vet. Med. Sci. 60 (10). pp 1097-1105.

TOH, H.M., KODAMA, J.M., YANAGISAKO, $\mathrm{M}$ and OHMORI, T. (1992): Anatomical study of the accessory mental foramen and the distribution of its nerve. Okajimas Folia Anat. Jpn, 69: 85-88 